
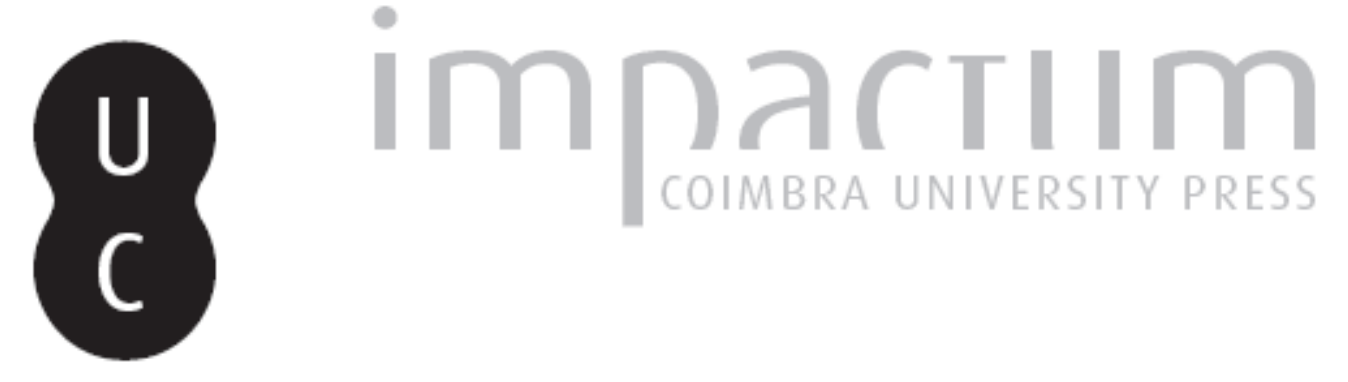

\title{
O tesouro romano, em prata, de Bracara Augusta
}

\author{
Autor(es): $\quad$ Morais, Rui
}

Publicado por: Faculdade de Letras da Universidade de Coimbra

URL persistente:

URI:http://hdl.handle.net/10316.2/37672

DOI:

DOI:http://dx.doi.org/10.14195/1647-8657_41_10

Accessed : $\quad$ 26-Apr-2023 12:47:41

A navegação consulta e descarregamento dos títulos inseridos nas Bibliotecas Digitais UC Digitalis, UC Pombalina e UC Impactum, pressupõem a aceitação plena e sem reservas dos Termos e Condições de Uso destas Bibliotecas Digitais, disponíveis em https://digitalis.uc.pt/pt-pt/termos.

Conforme exposto nos referidos Termos e Condições de Uso, o descarregamento de títulos de acesso restrito requer uma licença válida de autorização devendo o utilizador aceder ao(s) documento(s) a partir de um endereço de IP da instituição detentora da supramencionada licença.

Ao utilizador é apenas permitido o descarregamento para uso pessoal, pelo que o emprego do(s) título(s) descarregado(s) para outro fim, designadamente comercial, carece de autorização do respetivo autor ou editor da obra.

Na medida em que todas as obras da UC Digitalis se encontram protegidas pelo Código do Direito de Autor e Direitos Conexos e demais legislação aplicável, toda a cópia, parcial ou total, deste documento, nos casos em que é legalmente admitida, deverá conter ou fazer-se acompanhar por este aviso.

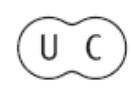




\section{CONIMBRIGA}

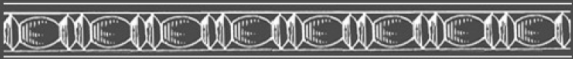

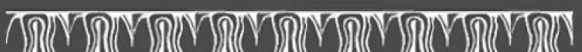
2

INSTITUTO DE ARQUEOLOGIA

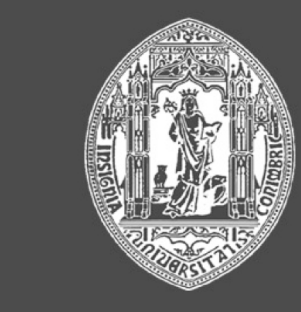

VOLUME XLI - 2002

F A C U L D A E D E LETRAS UNIVERSIDADE DE COIMBRA 
RUI MORAIS

Assistente da Universidade do Minho

O TESOURO ROMANO, EM PRATA, DE BRACARA AVGVSTA

"Conimbriga" XLI (2002) p. 219-235

RESUMO: Estuda-se um valioso tesouro de prata encontrado em Braga nos meados do século XVIII. Este tesouro, constituído por quatro grupos distintos de peças, foi fundido, com excepção de um "vaso de sacrifício" do qual não conhece o paradeiro.

A descrição das peças constituintes do tesouro leva-nos a crer da sua autenticidade. Ensaia-se assim um estudo tendo em conta a natureza do repertório figurativo e o significado do seu imaginário.

Propõe-se, ainda, a natureza religiosa deste tesouro e faz-se uma tentativa de ensaio cronológico e sua contextualização na cidade tendo em conta os vestígios arqueológicos exumados ao longo de décadas de escavações.

SumMARY: A valuable silver treasure found in Braga, dated from the mid-18th century, is studied.

This treasure, made up of four different group of pieces, was all melted except for a "sacrifice vessel", whose whereabouts remains unknown.

The detailed description of the pieces that constitute the treasure leads us to conclude that it must have really existed. A study is, thus, essayed taking in account the nature of its figurative repertoire and the meaning of its imaginary.

Not only is a religious reading of this treasure suggested, but also an attempt to date it chronologically and to contextualize it in the city is carried away, taking in account the archaeological evidences unburied throughout decades of excavations. 
(Página deixada propositadamente em branco) 


\section{O TESOURO ROMANO, EM PRATA, DE BRACARA AVGVSTA}

\section{Introdução}

No dia 2 de Julho de 1750 dava-se notícia num suplemento da Gazeta de Lisboa de um "precioso tesouro" encontrado em Braga junto ao "Convento das Freiras da Conceiçam" (actualmente conhecido como Convento da Regeneração), no local onde existem vestígios da muralha romana (vide apêndice I e II). A importância deste achado justificou que, em 1897, Pedro Azevedo lhe faça referência na revista O Archeólogo Português, num trabalho intitulado "Notícias archeologicas colhidas em documentos do seculo XVIII" (1897: 247-248).

Segundo os dados ali reunidos, o tesouro, encontrado por quatro "homens do campo, cavando", era constituído por uma quantidade de peças em prata pesando na sua totalidade 240 marcos, ou seja, cerca de $57 \mathrm{~kg}$.

Como se depreende da descrição, o tesouro comportava quatro grupos distintos de peças:

- o 1. ${ }^{\circ}$ era composto por quatro estatuetas de "finíssima prata, de 6 palmos de altura" (cerca de 1,32 cm), uma representando a imagem de uma mulher, duas de centauros e outra de um fauno;

- o $2 .^{\circ}$, por vinte "cascos" ou "elmos", "grossos e lavrados com suas folhagens de finíssimo buril", terminando num topo em forma de "copa de chapéo", ou em bico, como "morrioens".

- o $3 .^{\circ}$, por um número não especificado ("alguns") de pequenos vasos de formato oval, aos quais se atribui uma provável função sacrificial;

- por fim, o $4 .^{\circ}$ grupo de materiais estava representado por mais de trinta lâminas "do tamanho de hum quarto de papel" e outras pequenas, "como a palma da mam". 


\section{A autenticidade do tesouro}

À semelhança de outros tesouros do mundo romano, este também foi fundido, fazendo-se apenas referência a um "vaso de sacrifício" comprado a um ourives de Chaves, "do qual assegura hum Pintor, filho de Pays estrangeiros, nam haver visto em Roma, donde agora veyo, peça similhante".

A ausência de outras referências até aos dias de hoje quanto à importância deste tesouro parece resultar de um certo cepticismo relativamente à veracidade do mesmo. Todavia, uma análise mais atenta sobre o significado e a contextualização iconográfica dos objectos encontrados leva-nos a admitir a sua autenticidade.

\section{II.1. As estatuetas}

O conjunto de quatro estatuetas referidas no $1 .^{\circ}$ grupo encontram, pelo seu repertório figurativo, paralelos em exemplares documentados no mundo romano, designadamente duas estatuetas actualmente em Paris (Kaufmann-Heinimann, 1989: 97, n. ${ }^{\circ}$ 27; 182-183, n. ${ }^{\circ} 129$ ): uma de Mercúrio, proveniente do tesouro de Berthouville, em depósito no Gabinete das Medalhas da Biblioteca Nacional (Est. I, 1); e outra, de Fortuna, de Sainpuits (Yonne), actualmente no Louvre (Bj 2107) no Departamento das Antiguidades Gregas, Etruscas e Romanas (Est. I, 2).

A estatueta de Mercúrio, em prata e com $56,3 \mathrm{~cm}$ de altura, possui vestígios de douradura na cabeça e caduceu e é oca no seu interior. Foi fabricada a partir de diferentes elementos através do processo de rebatimento, posteriormente unidos com a ajuda de entalhes de peças de madeira ou ferro de cabo arredondado, por martelagem e soldadura. $\mathrm{O}$ seu acabamento foi finalizado recorrendo-se à cinzelagem e polimento (id.: 97). A estatueta de Fortuna, com $57,5 \mathrm{~cm}$ de altura, também oca no seu interior, foi fundida em bronze e coberta por uma fina placa de prata, recoberta por abundantes vestígios de placagem dourada (id.: 182).

Para além destes significativos testemunhos, conhecem-se outros exemplares fabricados em bronze com características análogas (id.: 97; 183), e a referência a um outro tesouro em prata constituído por vasos dedicados a Mercúrio e estatuetas do deus, descoberto nas proximidades de Limoges, em 1829, cujos vasos foram fundidos e o destino das estatuetas desconhecido (id.: 97). 


\section{II.2. Os capacetes}

A presença de cerca de vinte capacetes com cuidada decoração a buril não encontra paralelos na bibliografia consultada sobre os tesouros em prata do mundo romano.

Assim, apresentamos duas hipóteses igualmente prováveis: a $1^{\underline{a}}$ aceitando que de "cascos" ou "elmos" efectivamente se trata; a $2^{2}$ admitindo tratar-se de recipientes hemisféricos.

No caso da $1^{\underline{a}}$ hipótese os capacetes não seriam de prata mas, à semelhança de outros, seriam antes de ferro com revestimento de bronze, de modo a provocar um contraste amarelo-esbranquiçado, como se efectivamente de ouro ou prata se tratasse (Kunzl, 1978: 96).

A indicação da decoração nestes "capacetes" permite, todavia, afastar a possibilidade de se tratar de simples capacetes usados por legionários. Efectivamente, o uso de capacetes decorados restringia-se a outras corporações mais elevadas, representadas por oficiais, soldados de tropas auxiliares, ou mesmo unidades especiais, como a tropa pretoriana em Roma (id.: 94). Dentre estes, sabemos que eram sobretudo os cavaleiros das tropas auxiliares que davam importância ao seu capacete (id.: ibidem).

A referência específica a "cascos" ou "elmos", "grossos e lavrados com suas folhagens de finíssimo buril", terminando num topo em forma de "copa de chapéo", ou em bico, como "morrioens", permite supor que se trataria de diferentes tipos de capacetes em uso no período alto-imperial: os primeiros (Est. I, 3), em forma de "copa de chapéo", poderiam corresponder a capacetes da época de Nero e dos Flávios, semelhantes a representações em baixos-relevos na região da Renânia (id.: 96); os segundos (Est. I, 4), terminando em bico, como "morrioens", podiam testemunhar outro tipo de capacetes usado pelas tropas auxiliares no tempo de Trajano (id.: ibidem) e Marco Aurélio, como se depreende a partir de alguns baixos-relevos da Coluna de Trajano e do Arco de Constantino, este último retirado de um antigo Arco de Triunfo de Marco Aurélio.

A menção a um capacete rematado por "huma grande pedra vermelha que aqui se nam conhece" podia ainda querer significar a presença de um outro tipo de capacete, neste caso de um simples centurião ou de um clássico capacete de um legionário do século I d. C., que, por vezes, apresentavam alguns elementos exóticos, como seja a presença de botões vermelhos (id.: 94). 
As numerosas inscrições de soldados pertencentes a unidades auxiliares recrutados entre os Bracari são um testemunho inequívoco da sua presença nos exércitos romanos (Le Roux, 1980). Estes foram recrutados na cidade de Bracara Augusta (Bracaraugustanorum) e no seu conventus (Bracarum), para o desempenho de variadas funções, quer na sua vertente militar, quer pela sua vinculação à própria administração civil (id.: ibidem). A referência a cerca de vinte "cascos" ou "elmos" com cuidada decoração a buril, típicos, como vimos, das corporações mais elevadas dos exércitos, poderia, deste modo, testemunhar, ainda que indirectamente, a forte ligação da cidade ao recrutamento de exércitos na organização provincial.

A $2^{2}$ hipótese é apoiada pela existência de recipientes hemisféricos bem documentados no mundo romano, em particular nos séculos II e III (vid. Baratte, 1989: 119-122, figs. 58-61).

Ainda que datados do século II a. C., é de salientar a existência de três exemplares em prata dourada de origem pergamanha encontrados, em 1811, em Falerii Novi, no Lácio, actualmente depositados no Museu Nacional de Arqueologia de Nápoles (Coarelli, 1981: 529; Pappalardo, 1989: 93-94; Cat. 214, n. ${ }^{\circ}$ 65-66). Destacamos estes exemplares (Est. II, 1 e 2) pelo facto de possuírem uma requintada decoração a buril, com a representação de folhas de acanto, cujo topo está encimado por uma pedra de rubi, fazendo-nos recordar as referências a "cascos" ou "elmos", grossos e lavrados com as suas folhagens de finíssimo buril" e a menção a um capacete rematado por "huma grande pedra vermelha que aqui se nam conhece".

\section{II.3. Os "vasos" de formato oval}

A referência a pequenos vasos ovalados parece poder enquadrarse num tipo específico da baixela romana em prata. Trata-se de pratos pouco frequentes (Baratte, 1989: 158) de formato oval e asas em forma de aba decorada que, de acordo com a bibliografia consultada, poderiam adquirir dimensões variadas, cujos protótipos podemos encontrar em formas de vidro (vid. Isings, 1957). O exemplar de menores dimensões (Est. III, 1), actualmente no Museu Municipal de Lillebonne, provém de um pequeno tesouro encontrado nessa mesma localidade (id.: 1989: 107, n. ${ }^{\circ} 38$ ), muito próximo, pela sua altura, a um outro existente no Museu de Turim (id.: 1978: fig. 7; id.: 1989: 107). Outros dois 
exemplares, de maiores dimensões, são dados como provenientes do pequeno tesouro de Saulzoir (id.: 158-159, n. ${ }^{\circ} 105$ ) e do tesouro de Rhetel (id.: 161-163, n. ${ }^{\circ} 107$ ); o primeiro (Est. III, 2) encontra-se em depósito no Museu de Belas Artes de "Valenciennes" (inv. 46, 8.15) e o segundo (Est. III, 3) no Museu das Antiguidades Nacionais, em "Saint-Garmain-en-Laye" (inv. 85793).

\section{II.4. As lâminas}

A presença de cerca de trinta lâminas de prata, algumas das quais decoradas com cenas de caçadores fazendo montarias, é deveras significativa. De facto, a simples menção a lâminas de prata, permite, desde logo, inferir a veracidade deste tesouro e enquadrá-lo no contexto dos tesouros de tipo votivo, como aqueles documentados em "Mauer na der Url", "Weissenburg" (Est. IV, 1) e "Hagenbach" (vide autores em Baratte, 1989: 80).

\section{A natureza do repertório figurativo e o significado do seu imaginário}

Para além das considerações acima referidas sobre a veracidade deste "precioso tesouro", permanece por analisar a consistência do repertório figurativo de algumas das peças aí encontradas. Nesse sentido, cabe destacar a presença das duas estatuetas com a representação de centauros.

No mundo romano, o motivo dos centauros tem um papel predominante na evocação das cenas báquicas, incluindo, entre outros, a figura de sátiros e ménades característicos do repertório neo-ático e retomados em mosaicos romanos e sarcófagos datados dos séculos II e III (vid. Van de Grift, 1984: 381-382).

A representação de centauros associados ao cortejo báquico não é, todavia, tema exclusivo do mundo romano. De facto, este tema encontra-se já explorado no mundo grego como se documenta num Krater de sino ático de figuras vermelhas do pintor de Filottrano, datado de cerca de 369 a. C. (Est. IV, 2) e actualmente no Museu Arqueológico Nacional de Ferrara (inv. 10459) (vid. Rausa, 1989: 88, n. ${ }^{\circ}$ 37; 89). 
A presença de um centauro em prata, actualmente em depósito no "Kunsthistorisches Museum" em Viena, no grande tesouro descoberto, em 1811, em Falerii Novi (Est. V, 1 e 2), vem ao encontro das diferentes notícias fornecidas pelas fontes literárias antigas sobre a maciça importação em Itália de obras de arte grega, em particular de prata, iniciada a partir da II guerra púnica com o saque de Siracusa e de Taras e, sobretudo, no decurso das guerras do Oriente, do início do século II a. C. ameados do século I d. C. (Coarelli, 1981: 530). A importação destas obras de arte não ficou, todavia, restrita ao mundo itálico. De facto, a presença, entre outros tesouros encontrados na Península Ibérica, de uma pátera (Est. V, 3) com a representação de centauros, proveniente do tesouro de Pero Tito (Santisteban del Puerto, Jaén) vem redimensionar a importância destes achados no contexto da Idade do Ferro Peninsular.

No que respeita à torêutica romana em prata, os centauros estão documentados em exemplares encontrados nos tesouros de Berthouville, Baltimore e Pompeia. Do primeiro tesouro (cerca de Brione, Eure) destacam-se dois Skyphoy, actualmente no Gabinete das Medalhas na Biblioteca Nacional de Paris, nos quais os centauros, para além de figuras principais na decoração, estão representados de forma orquestrada como membros proeminentes do ciclo báquico (Van de Grift, 1984: 381, Est. 51, figs. 1-6, Est. 52, figs. 7-10; Baratte, 1989: 82-84, n. ${ }^{\circ} 17$ ). Nos tesouros de Baltimore e Pompeia, os centauros figuram em Kanthary: do primeiro provém um exemplar, actualmente depositado na Walters Art Gallery (inv. 57.929), no qual se representa um par de centauros a puxar a biga de Dioniso (Van de Grift, 1984: 382); do segundo, destacam-se dois exemplares, descobertos na Casa dell'Argentaria ou Domus P. Antisti Maximi e L. Lac(li) Tro(phimi), actualmente no Museu Nacional de Nápoles (inv. 25376 e 25377), com a representação de centauros masculinos e femininos com cupidos montando os seus dorsos (id.: ibidem, Est. 53, figs. 11-14; Pappalardo, 1989: 94, n. ${ }^{\circ} 32$; 95, n. $\left.{ }^{\circ} 33 ; 210-211\right)$.

O mesmo repertório figurativo está também bem documentado em versões romanas de grupos escultóricos inspirados em originais helenísticos (García y Bellido, 1979: 429-430), que consistem na representação de dois centauros masculinos, um velho e outro novo, cada qual montado por um cupido, tal como nos dois Skyphoy provenientes do tesouro de Berthouville (Van de Grift, 1984: 382). Destacam-se os centauros descobertos na Vila de Adriano em Tivoli, actualmente no 
Museu Capitolino em Roma, bem como as várias réplicas encontradas na Colina Caelius, na Vila de Domiciano (em Albano) e na réplica mais completa deste grupo actualmente no Museu do Louvre (id.: ibidem; 386, Est. 53, figs. 15-16; Garcia e Bellido, 1979: 429-430, n. ${ }^{\circ}$ 744-746).

Como se depreende deste repertório figurativo e, como bem sublinha Jon Van de Grift (1984) num estudo sobre a alegoria dos centauros presentes nos Skyphoy de Berthouville, os centauros eram frequentemente apresentados segundo um modelo dualista e simultaneamente antitético. É nesta perspectiva, aliás, que devemos encarar a referência a dois centauros encontrados no tesouro de Bracara Augusta, e, como tal, prova inequívoca da sua veracidade.

\section{A natureza religiosa do tesouro}

As várias dezenas de peças que constituem este tesouro e a sua variabilidade formal e qualitativa permitem-nos afirmar, com alguma segurança, que se tratava do tesouro de um dos templos da cidade. $\mathrm{Na}$ verdade, conhecem-se, no contexto do mundo romano, numerosos outros tesouros com características análogas ao de Braga. Dentre estes, o mais significativo está representado pelo tesouro de Berthouville, aqui já referido. Este tesouro foi descoberto em 21 de Março de 1830 por Prosper Taurin, um agricultor da pequena localidade de Villaret, a algumas centenas de metros a noroeste de Berthouville (Baratte, 1989: 79-80). O exame das várias dezenas de peças de metal variado, de diferente qualidade e cronologia, demonstrou tratar-se do tesouro de um santuário gálico dedicado a Mercúrio Canetonensis (Van de Grift, 1984: 377; Baratte, 1989: 79). Este tesouro, enterrado nos finais do século II (Van de Grift, 1984: 377) ou mesmo inícios do III (Baratte, 1989: 80), pesando cerca de $25 \mathrm{~kg}$ de prata, é, conjuntamente com o tesouro de Notre-Dame d'Alençon, um dos melhores e dos mais ricos exemplos de tesouro de templos de época romana (id.: ibidem).

Neste tipo de tesouros os fiéis podiam oferecer ao deus as suas próprias pratas, muitas das vezes compradas em oficinas estabelecidas junto aos santuários que vendiam aos peregrinos as baixelas para as suas oferendas (id.: ibidem). Estas obtinham frequentemente a forma de estatuetas em bronze ou em prata, ou de simples lâminas de prata ornamentadas ou não (id.: ibidem). A presença de lâminas de prata associadas a estatuetas e baixelas de prata está documentada noutros tesouros, 
também eles inequivocamente relacionados com oferendas a divindades, como testemunham os tesouros de Mauer an der Url e Weissenburg, ou a presença única de lâminas votivas, como no caso específico do tesouro de Hagenbach (id.: ibidem).

Do exposto parece-nos que as referências ao aparecimento de estatuetas, vasos e lâminas de prata neste tesouro de Bracara Augusta deve ser valorizado e devidamente contextualizado.

Pensamos, assim, que estamos perante o tesouro proveniente de um dos templos da cidade, eventualmente dedicado a Mercúrio, como se pode testemunhar pela existência de uma dedicatória (CIL II, 2417; $A E, 1973:$ 310) na qual se faz referência a esta divindade, encontrada num muro da "cerca do Seminário do Campo de Santiago" e actualmente em depósito no Museu Pio XII, em Braga (Tranoy, 1981: 315; Santos, Le Roux e Tranoy, 1983: 188, n. ${ }^{\circ}$ 8). O destino deste tesouro, porém, seria igual à de tantos outros, encontrados até ao século XIX, como no caso do tesouro, já referido, encontrado perto de Limoges, cujo espólio, constituído por vasos de prata dedicados a Mercúrio, acabou por ser fundido (Baratte, 1989: 80).

\section{Tentativa de ensaio cronológico}

Como referimos, o tesouro comportava, pelo menos, quatro tipos distintos de peças.

O primeiro, constituído pelo conjunto de quatro estatuetas, encontra paralelos temáticos em exemplares aqui já mencionados, em especial a representação de centauros nos Skyphoy de Berthouville e nos Kanthary de Baltimore e Pompeia, datados do século I (id.: ibidem, 1989: 79). Destes, o tesouro de Berthouville comporta outro tipo de achados, entre os quais a já referida estatueta de mercúrio, desta vez datada do fim do século II / inícios do III (Kaufmann-Heinimann, 1989: $\left.97,{ }^{\circ}{ }^{\circ} 27\right)$ e que encontra paralelo na outra estatueta proveniente de Saintpuits (Yonne), datada do século III (id.: 182-183, n. ${ }^{\circ} 129$ ). Estes dados, juntamente as conhecidas versões de grupos escultóricos de centauros datados da época de Adriano e de mosaicos e sarcófagos datados do século II (Van de Grift, 1984: 382), permitem enquadrar as estatuetas de Bracara Augusta em data não posterior ao século III.

O segundo e terceiro grupos, constituídos, respectivamente, por cerca de vinte "cascos" ou "elmos" possivelmente datáveis (Kunzl, 
1978: 96) do período de Nero e Flávios e a época de Adriano (ou recipientes hemisféricos bem presentes em contextos nos séculos II e III), e por um número não especificado de "vasos" ovais, típicos das baixelas dos séculos II e III (Baratte, 1989: 38), não contradizem a anterior cronologia. A presença de cerca de trinta lâminas em prata, características, como vimos, de tesouros de carácter votivo que não ultrapassam o século III d. C. (Enrico, 1993: 44), vem, desta forma, corroborar as datas anteriormente referidas.

Quanto aos motivos determinantes da ocultação deste tesouro, será legítimo adiantar a hipótese de se tratar de tesouro depositado na eminência de um ataque. A sua deposição poderá ter ocorrido posteriormente ao século III, directamente relacionada com as primeiras rupturas do limes romano e consequentes invasões germânicas que saquearam a Gália e a parte este da Hispânia. Foram estas incursões que levaram, aliás, o Estado romano, de acordo com as autoridades locais, a estabelecer um conjunto de medidas defensivas, entre as quais a fortificação das cidades através de linhas defensivas de muralhas. Neste contexto, Bracara Augusta não será excepção, erguendo uma poderosa fortificação, cuja fundação data de finais do século III/inícios do IV.

\section{Contextualização do tesouro na cidade}

Um estudo como este, sobre um tesouro em prata do qual apenas temos conhecimento a partir de uma notícia colhida num documento do século XVIII, coloca duas questões essenciais: a primeira prende-se, naturalmente, com a veracidade da notícia; a segunda com a contextualização do tesouro na cidade, tendo em conta os vestígios arqueológicos exumados ao longo de décadas de escavações.

Se, para a primeira questão, expusemos os argumentos que julgámos pertinentes, no sentido de optar pela sua veracidade, a segunda ficou por abordar.

Para esta questão possuímos alguns argumentos que importa considerar: uma taça de prata encontrada na insula $\mathrm{V}$ do conjunto termal do Alto da Cividade (Morais, no prelo) e outros elementos que inequivocamente documentam atelies especializados em actividades metalúrgicas no interior da malha urbana da cidade. A estes acrescente-se o fragmento de uma estátua equestre, igual a tantas outras que deveriam ter adornado várias cidades em todo o Império. 
A presença desta taça de prata (Est. VI) é deveras significativa, na medida em que revela a importação de artigos de luxo na cidade, testemunhando a existência de uma população economicamente diversificada disposta a pagar preços elevados pela sua aquisição.

Por outro lado, a identificação de vestígios de atelies especializados em actividades metalúrgicas (Est. VII), isolados na periferia dos quarteirões de habitação, documentam, à semelhança de outras cidades do mundo romano (Alarcão, 1984: 21; id., 1994: 14; Krause, 2001: 5657; Pettinau, 1993: 76), a relativa importância na cidade das actividades relacionadas com as artes do fogo. Estes vestígios correspondem a cadinhos para fundição de ouro e bronze e moldes para a fundição de elementos de sítulas, designadamente a parte superior de lâminas decoradas e suportes anelares de armelas, encontrados na periferia e no interior da malha urbana da cidade, junto ao fórum.

Excepcional é também o achado do fragmento de uma estátua nas escavações realizadas na insula das Carvalheiras (Est. VIII, 1). À semelhança de muitos outros bronzes romanos, o fragmento apresenta uma superfície coberta por uma placagem em folha de ouro aplicada numa superfície previamente preparada com uma matéria adesiva, técnica muito utilizada em estátuas de bronze de época romana (Eluère, 1990: 23). Este fragmento, proporcionalmente idêntico à pata dianteira do cavalo da estátua equestre de Marco Aurélio (Est. VIII, 2), actualmente no Museo del Pallazzo dei Conservatori (Kleiner, 1992: 271-272, n. ${ }^{\circ} 236$; Huskinson, 1993: Est. XXIII, n. ${ }^{\circ} 338$; 335; Elsner, 1998: 78-79, Fig. 50), deveria fazer parte da estátua a um imperador colocado em praça pública. De facto, como refere Patrick Le Roux (1996: 369), "teriam existido em Braga magistrados e uma ordo decurionum, bem como estátuas em honra de personagens importantes, ou de imperadores, colocadas em locais da praça pública".

Com excepção da taça de prata que admitimos deva ter sido importada por razões já expostas (Morais, no prelo), não podemos afirmar, com segurança, a proveniência deste tesouro. Contudo, pode considerar-se muito provável que algumas das peças referidas tenham sido fabricadas na cidade, dados os vestígios de uma actividade metalúrgica, encontrados na periferia e no âmago da cidade. 


\section{APÊNDICE I}

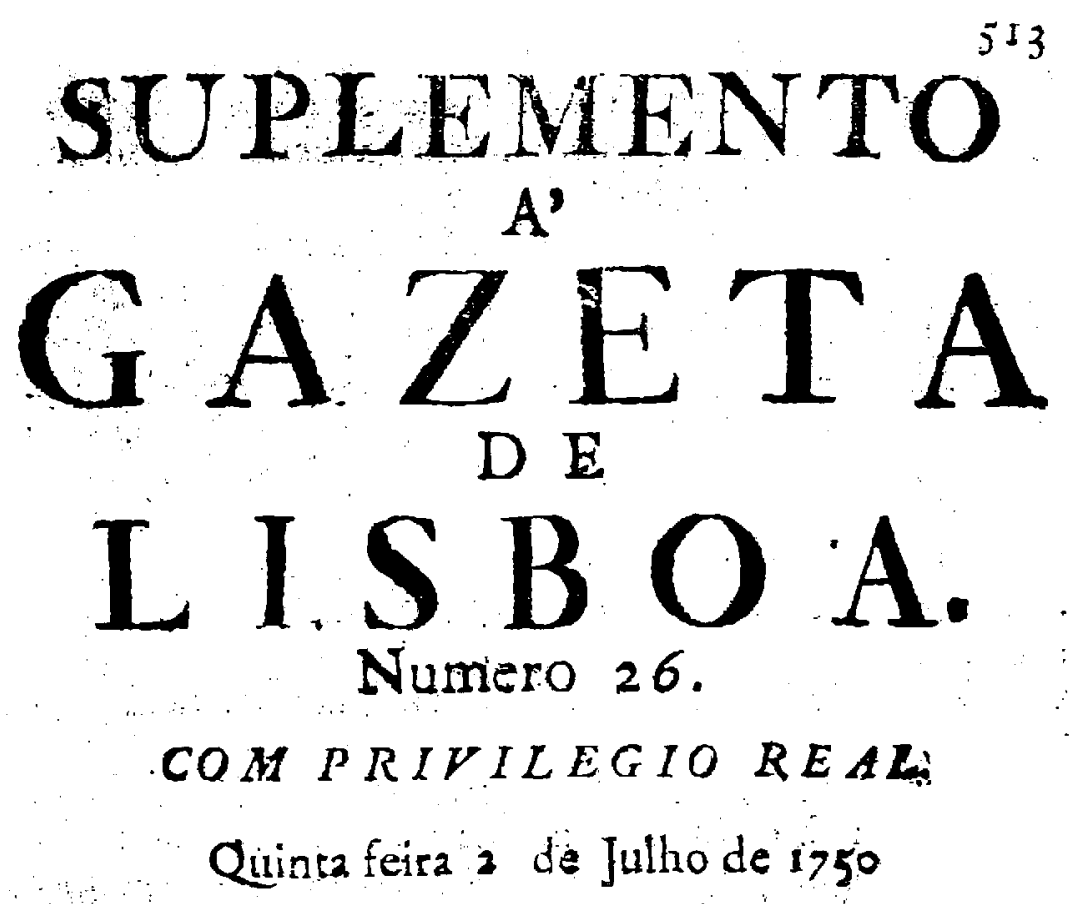




$$
\begin{aligned}
& \text { I) in } 1 \text { U C } A \text { L. } \\
& \text { Braga } 20 \text { ihe Fibilio. }
\end{aligned}
$$

- Tefta Cidude junto ao Convento das Freiras da Con1 ceiçam, no fitio, a que o Povo da o nome de Civiakale, onde airda ao prefente exifte huma granue parte de muralha pntiga do tempo dos Rumanos, defobrín 4 homens do campo, cavando, hum preciolo refouro de peças maravilhozas pela lua forma, entre as quas havia 4 eftatuas de finifima prata, de 6 palmos de altura: huma de Mulher, duas de Centauros, e outra de hum Fauno Com eftas aparecêram tambern $20 \mathrm{Calcos}$, ou Elnos de prata, grallos; e lavrados com fuas folhagens de finiftima buril; algomas do tamanho da copa de hum chapéo, outros de bico, coma Morrioens: alguns Vafos pequenos ovados, que paṛeciam deftinados para facrificios. Aparecêra mais trinta e tantas lamioas de prata do camanho de hum quarta de papel, e outras pequenas, conno a palma da mam. Em algumas fe viam primorozanente debuxados Caçadores fazendo montarias: em outras fomente alguns Javalís. Digem que pezava tudo 240 marcos. Os descobridores re partîram entre fro achado, evendeu hum delles a hum ouiver da prata defa Cidade o pezode 23 marcos do finimi ma prata: os outros fe efpalháram por yarias partes, enico

brine

520

brindo o que tinham achado, e hum as fo vender a hum ourives em Cháves; onde fe acha o Senhor Arcebofpo Rrimaz, que havendo tido noticia defte tefonbrimento fez logo comprar as peças, que havia em Chates, mandou orden a efta Cidade pria te the compraremtom das as jue aparecêram; o gue nani pôde confeguir, par te haverem ja fundido inuitas. $O$ Conego Joam Marcos Iplcam comprou ao mefino ourives, (a quem fe tinham vendido cm (egredo, hum Valo de Sacrificio, do quath allegúra hum Pintor, filho de Pays eftrangeiros, nam haver vifto em Rona, donde agora veyo, peça fimilhonte. As I aminas eram todas lavradas ao buril com tanto primor que talvez nem haja no prefente tenapo artifice, que as faça tam perfeitas. Em hum dos Cafquetes, ou Elrzos de prata havia no remate huma grande pedra vermelha que aqui fe nam conliece. 


\section{APÊNDICE II \\ Notícias archeologicas colhidas em documentos do seculo XVIII**}

\section{ANTIGUALHAS ACHADAS EM BRAGA}

a) Thesouro de objectos romanos

"Braga, 20 de Junho. - Nesta Cidade junto ao Convento das Freiras da Conceiçam, no sitio, a que o Povo dá o nome de Cividade, onde ainda ao presente existe huma grande parte de muralha antiga do tempo dos Romanos, descobriram 4 homens do campo, cavando, hum precioso tesouro de peças maravilhozas pela sua forma, entre as quaes havia 4 estátuas de finissima prata, de 6 palmos de altura: huma de Mulher, duas de Centauros, e outra de hum Fauno. Com estas aparecêram tambem 20 Cascos, ou Elmos de prata, grossos, e lavrados com suas folhagens de finissimo buril; algumas do tamanho da copa de hum chapéo, outras de bico, como Morrioens: alguns Vasos pequenos ovados, que pareciam destinados para sacrifícios. Aparecêram mais trinta e tantas laminas de prata do tamanho de hum quarto de papel, e outras pequenas, como a palma da mam. Em algumas se viam primorozamente debuxados Caçadores fazendo montarias: em outras somente Javalis. Dizem que pezava tudo 240 marcos. Os descobridores repartiram entre si o achado, e vendeu hum delles a hum ourives de prata desta Cidade o pezo de 23 marcos de finissima prata: os outros se espalharam por varias partes, encubrindo o que tinham achado, e hum as foy vender a hum ourives em Châves; onde se acha o Senhor Arcebispo Primaz, que havendo tido noticia deste descobrimento fez logo comprar as peças, que havia em Châves, e mandou ordem a esta Cidade para se lhe comprarem todas as que aparecêram: o que nam pôde conseguir, por se haverem já fundido muitas. O Conego Joan Marcos Falcam comprou ao mesmo ourives (a quem se tinham vendido em segredo, hum Vaso de Sacrifício, do qual assegura hum Pintor, filho de Pays estrangeiros, nam haver visto em Roma, donde agora veyo, peça similhante. As Laminas eram todas lavradas ao buril com tanto primor que talvez nam haja no presente tempo artifice, que as faça tam perfeitas. Em hum dos Casquetes, ou Elmos de prata, havia no remate huma grande pedra vermelha que aqui se nam conhece".

(Supplemento á Gazeta de Lisboa, n. ${ }^{\circ}$ 26, 2 de Julho de 1750).

In, AzEvedo, Pedro (1897)

"Notícias Archeologicas colhidas em documentos do séc. XVIII", O Archeólogo Português, 9-11, Set.-Nov., Lisboa, 1897, 247-248.

* “[Não póde dividar-se d'esta notícia, em virtude da natureza do periodico em que foi publicada. Este rico thesouro, que se perdeu, lembra o do Bosco-Reale (sec. I) que vi no Museu de Louvre em 1987. - J. L. de V.]”. 


\section{BIBLIOGRAFIA}

Alarcão (1984): Adília Alarcão - Colecções do Museu Monográfico de Conimbriga, Catálogo, Coimbra, 1984.

Alarcão (1994): Adília AlarCÃo - Museu Monográfico de Conimbriga, Colecções, Instituto Português de Museus, Lisboa, 1994.

ANDREAe (1998): BERNARD ANDREAE - "L'Art romain", L'Art et les Grandes Civilizations, (col. Lucien Mazenod), Citadelles \& Mazenod, Paris, 1998, n. ${ }^{\circ} 107$.

AZEVEDo (1897): PEDRo AZEVEDO - "Notícias archeologicas colhidas em documentos do seculo XVIII", O Archeólogo Português, 9-11, Set.-Nov., Lisboa, 1897, 247-248. BARATTE (1978): F. BARATTE - "L'argenterie romaine de Lillebonne", dans Centenaire de l'abbé Cochet, 1975, Actes du Colloque international d'archéologie, Rouen, 171-190.

- (1989): "III. 2 $2^{\mathrm{e}} 3^{\mathrm{e}}$ siècles", Tresors d'Orfevrerie Gallo-Romains, Ministère de la Culture, de la Comunication.../Éditions de la Réunion des musées nationaux, Paris, 1989, 82-84, fig. 17; 107, fig. 38; 158-160, fig. 105; 161-163 , fig. 107.

BRENDEl (1982): Отto BRENDEL - Introduzione all'Arte Romana, Salvatore Settis (ed.), Einaudi, Torino, 1982, n. ${ }^{\circ} 31$.

CoArelli (1981): F. CoArelli - "4. Arti Minori. A. Toreutica", Storia e civiltà dei Greci. La cultura ellenistica. Le arti figurative, 10, Bompiani, Milão, 1981, 514-535; fig. 70 e 71.

ELSNER (1998): JÁS ElSNER - "Imperial Rome and Christian Triumph. The Art of the Roman Empire AD 100-450", Oxford History of Art, Oxford/New York, 1998.

EluÈRE (1990): C. EluÈrE - Chercheurs D'Or et Orfevres. Des Temps Anciens, Musée des Antiquités nationales Saint-Germain-en-Laye (25 octobre 1990/21 janvier 1991), Réunion des musées nationaux, Paris, 1990.

ENRICO (1993): ANNA ENRICO - "Fortificazioni Romane in Germania", Archeo. Attualità del Passato, Anno VIII, n. ${ }^{\circ}$ (95), De Agostini - Rizzoli Periodici, Gennaio 1993, 44. Garcia y Bellido (1979): Antonio Garcia y Bellido - "Arte Romano", Enciclopedia Clásica, n. ${ }^{\circ}$ I, C. S. I. C., Madrid, 1979.

HUSKINSON (1993): J. HUSKINSON - "6. The Later Roman Empire", The Oxford History of Classical Art (ed. John Boardman), Oxford University Press, 1993, 297-344. IsINGS (1975): C. IsINGS - "Roman Glass from dated Finds", Archaeologica Traiectina, 2, Groningen - Djakarta, 1957.

Kaufmann-Heinimann (1989): AnNemarie Kaufmann-Heinimann - "Catalogue. 27. Mercure; 129. Statue de Fortuna", (in, Baratte, III, $2^{\mathrm{e}}-3^{\mathrm{e}}$ siècles), Tresors d'Orfevrerie Gallo-Romains, Ministère de la Culture, de la Comunication.../Éditions de la Réunion des musées nationaux, Paris, 1989, 97, fig. 27; 182-183, n. ${ }^{\circ} 129$. Kleiner (1992): Diana E. E. KLeINER - Roman Sculpture, Yale University Press, Londres, 1992.

Krause (2001): Marie-France Meylan Krause - "Les artisans dans la ville", as. Archaologie der schweiz..., Avenches, capitale des Helvètes, Basel, 24.2001.2, 50-81. 
KunZl (1978): ERnSt KunZL - "Les Armes Décorées du Soldat Romain", Dossiers de

l'Archéologie, n. ${ }^{\circ}$ 28, Fontaine-Les-Dijon/Bruxelles, 1978, Mai-Juin, 90-98. Liberati e Bourbon (1997): Anna Maria Liberati e Fabio Bourbon, Roma Antigua. Historia de una Civilización que conquistó el mundo, Folio, Barcelona, 1997, 93. Le Roux (1980): PATRICK LE RouX - "Les auxilia romains recrutés chez les Bracari et l'organisation politique du Nord-ouest Hispanique", Sep. das Actas do Seminário de Arqueologia do Noroeste Peninsular, Guimarães, 1980, 3-25, fig. 1. - (1996): "Las ciudades de la Callaecia romana durante el Alto Imperio", Gerión, 14, Departamento de Historia Antigua. Facultad de Geografía e Historia, Universidad Complutense, Madrid, 1996, 363-379.

Pappalardo (1989): U. PAPPAlARDo - "Gli argenti", Le Collezioni del Museo Nazionale di Napoli, De Luca Edizioni d'Arte Leonardo, Roma, 1989, 91-101; 210-211, n32a; 33a.

Pettinau (1993): Barbara Pettinau - "Dossier: L'oro dei Romani” (in, Lucia Pirzio Biroli Stefanelli), Archeo. Attualità del Passato, Anno VIII, n. ${ }^{\circ}$ (95), De Agostini - Rizzoli Periodici, Gennaio 1993, 76-77.

RADDATZ (1969): K. RADDATZ - "Die schatzfunde der Iberischen Halbinsel vom ende des dritten bis zur mite der ersten jahrhunderst von Chr. Geb. Untersuchungen zur hispanischemn toreutik", Madrider Forschungen, 5, Berlim, 1969.

RaUSe (1989): Federico Rausa - "Dionysos e le divinità olimpiche", Dionysos. Mito e Mistero, Fede Berti e Carlo Gasparri (ed.), Nuova Alfa Editoriale, Bolonia, 1989, 88, n. ${ }^{\circ} 37 ; 89$.

RIEgl (1980): A. RIEGL - Problemas de estilo. Fundamentos para una historia de la ordenación, G G Arte, Barcelona, 1980.

Santos, le Roux e Tranoy (1983): Luciano dos Santos, Pierre le Roux e Alain TRANOY - "Inscrições Romanas do Museu Pio XII em Braga", Bracara Augusta, vol. 37, n. ${ }^{\circ}$ 83-84 (96-97), Jan.-Dez., 1983, Braga, 188, n. ${ }^{\circ}$ 8; Est. IV, n. ${ }^{\circ} 10$.

Tranoy (1981): A. Tranoy - La Galice Romaine: Recherches sur le $N W$ de la Péninsule Ibérique dans l'Antiquité, Diffusion du Boccard, Paris, 1981.

VAN DE GRIFT (1984): J. VAN DE GRIFT - "Tears and Revel: The Allegory of the Berthouville Centaur Scyphi”, American Journal of Archaeology (A. J. A.), vol. 88, n. $^{\circ}$ 3, July, 1984, 377-388.

\section{ARTIGOS DE JORNAL}

Supplemento à Gazeta de Lisboa, n. ${ }^{\circ}$ 26, 2 de Julho de 1750.

\section{GUIAS DE MUSEUS}

(1954) Guías de los Museos de España.-1, Museo Arqueológico Nacional, Publicaciones de la Dirección General de Bellas Artes, 1954, 30; s/ n. ${ }^{\circ}$ estampa, n. ${ }^{\circ} 1$.

(1972) Museo Arqueológico Nacional. Las Nuevas Salas de Antiguedades Ibericas y Clásicas, Ministerio de Educación y Ciencia / Dirección General de Belas Artes, Madrid, 1972. 
EST. I

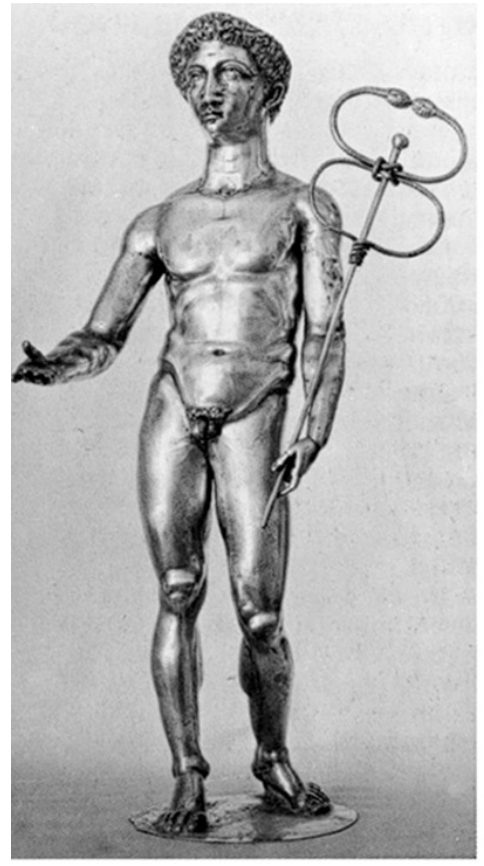

EsT. I-1

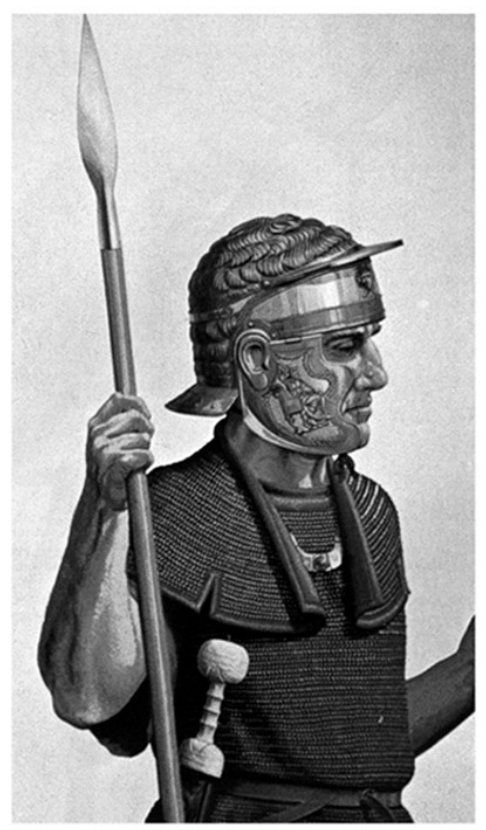

EsT. I-3

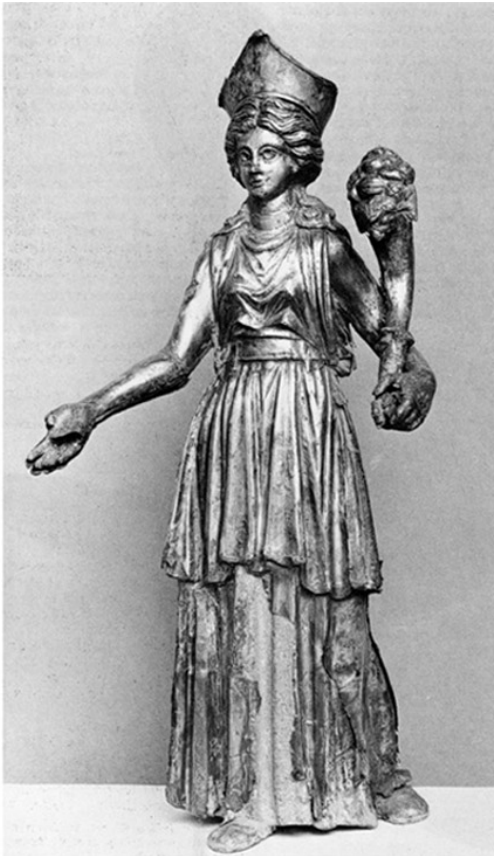

EsT. I-2

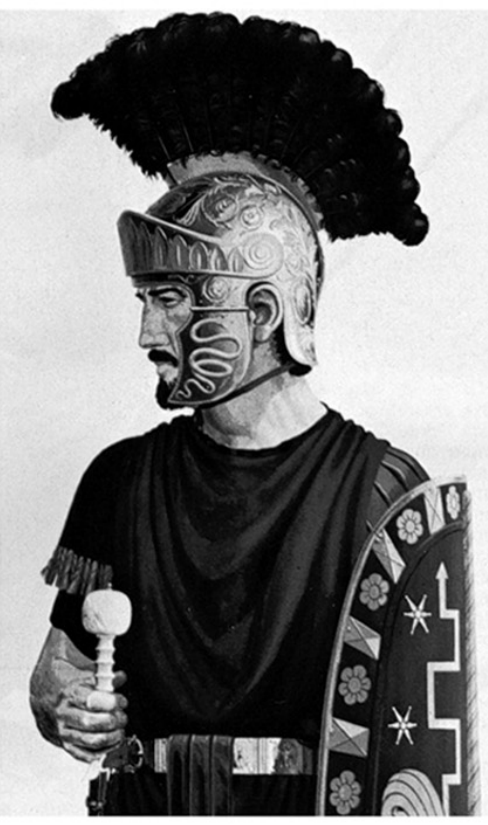

EST. I-4 
EST. II

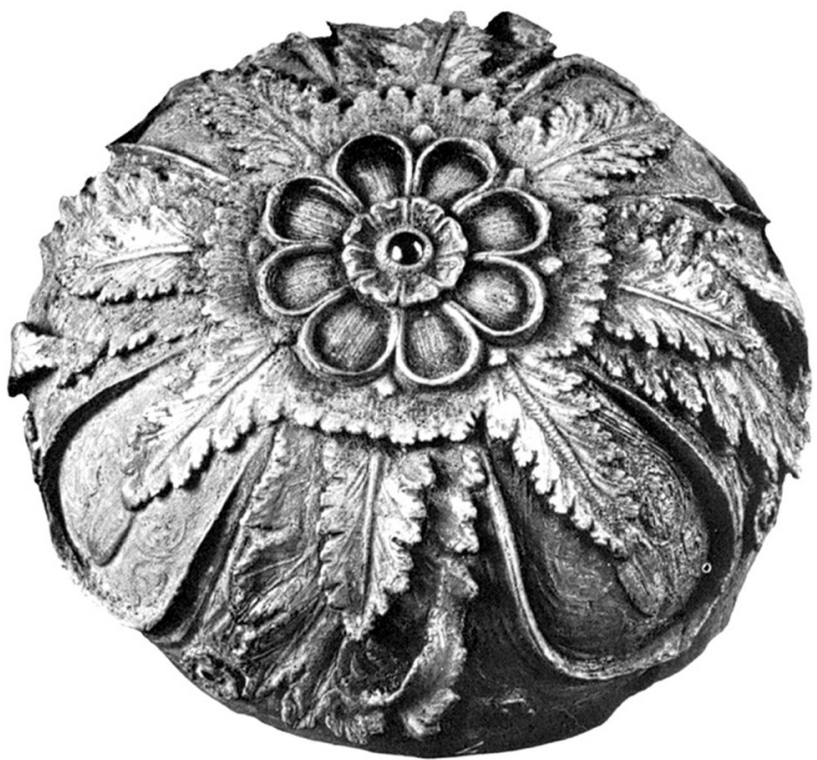

EsT. II-1

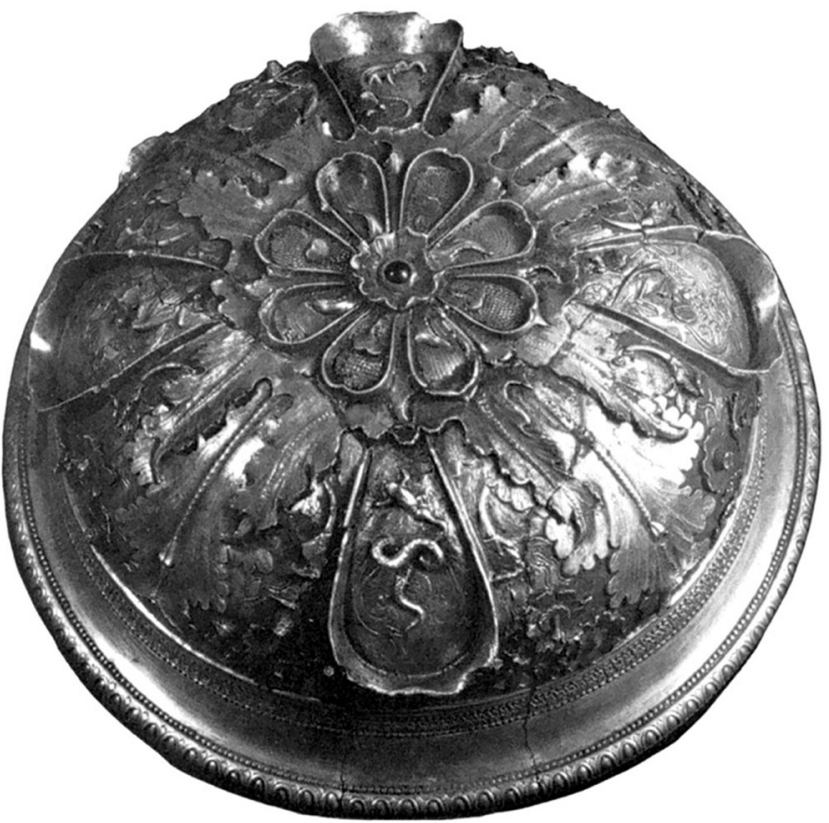

EsT. II-2 
EST. III

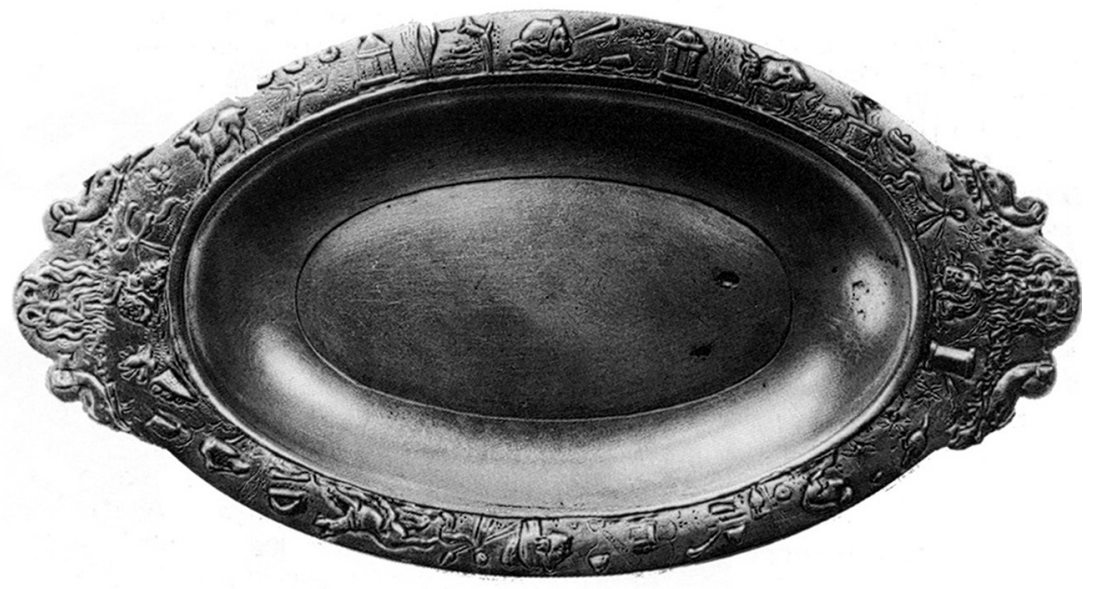

EsT. III-1

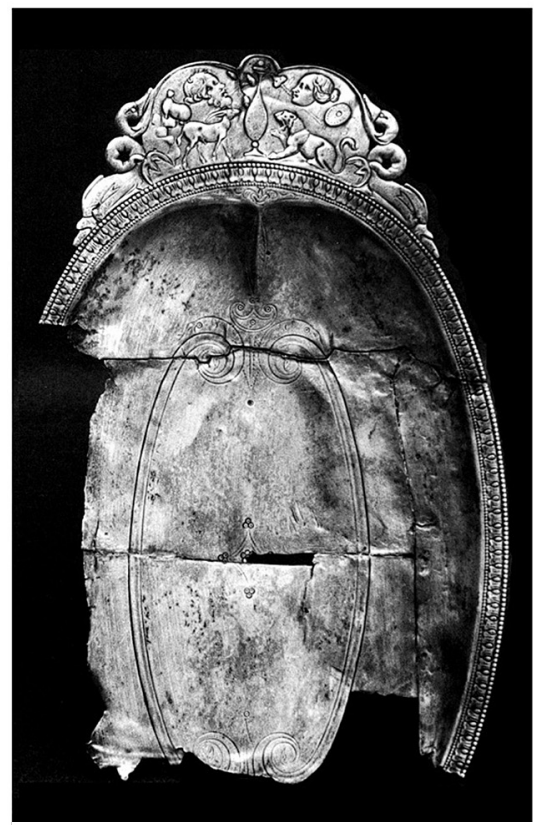

EsT. III-2

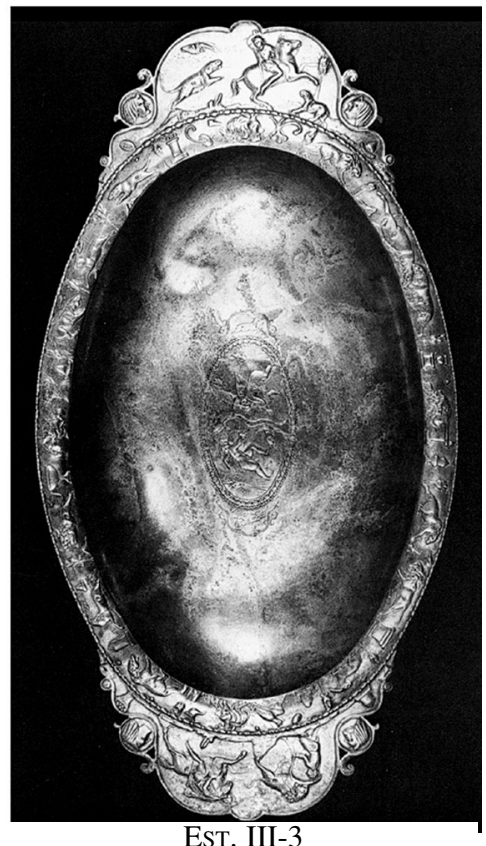

EST. III-3 
EsT. IV

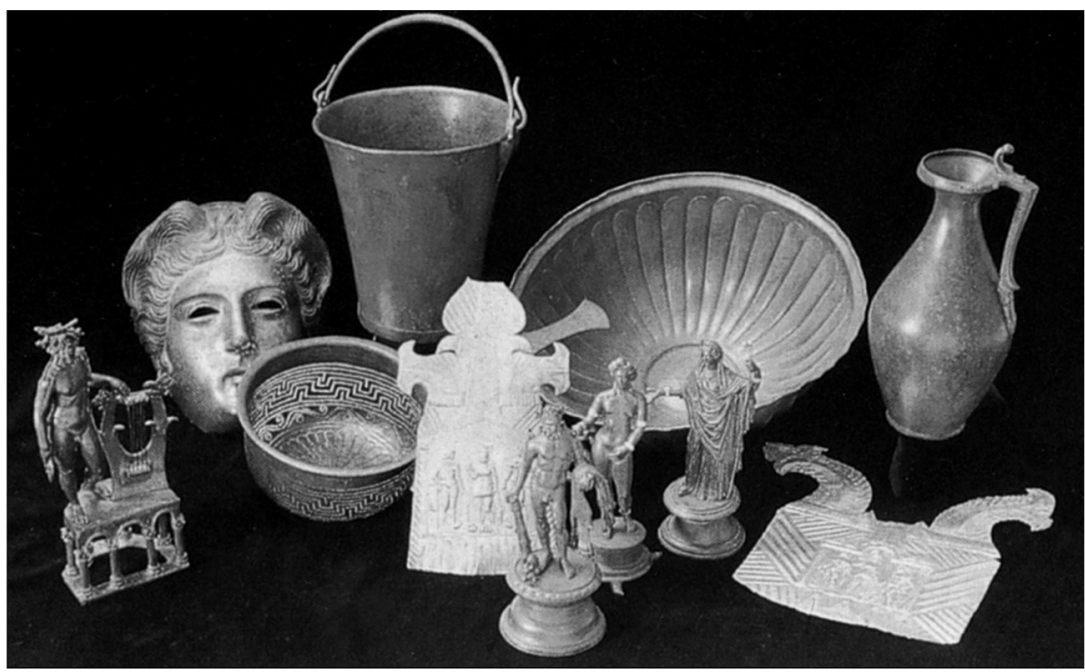

EsT. IV-1

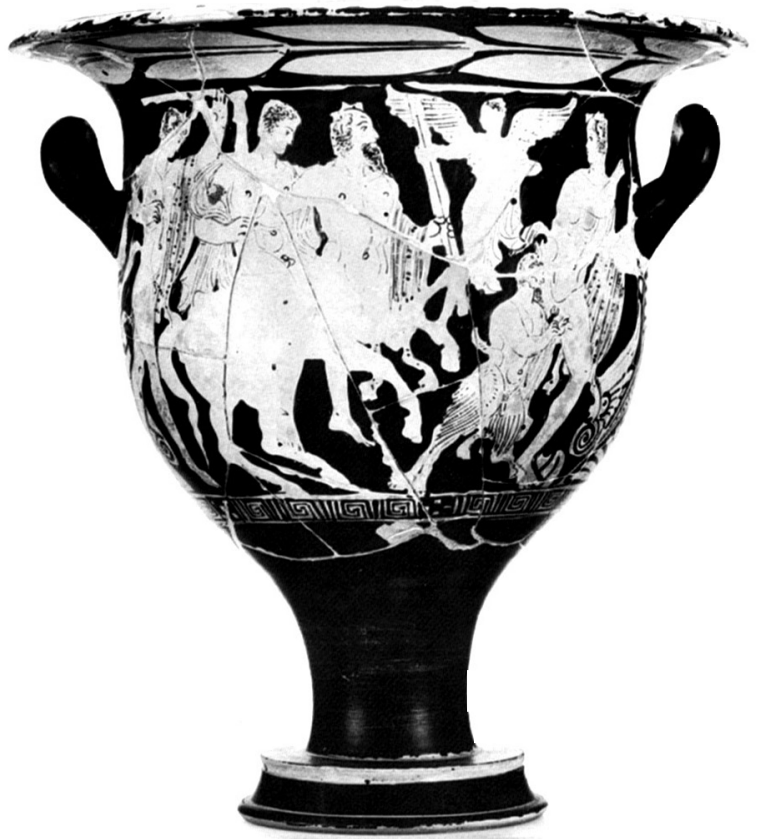

EsT. IV-2 


\section{Est. V}

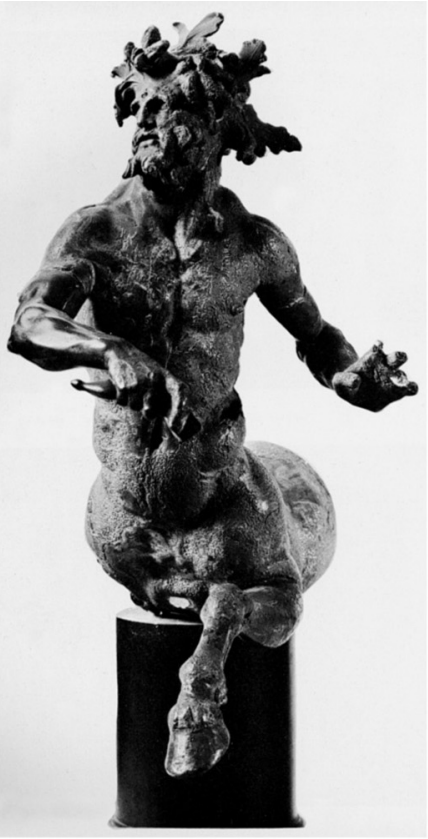

EsT. V-1

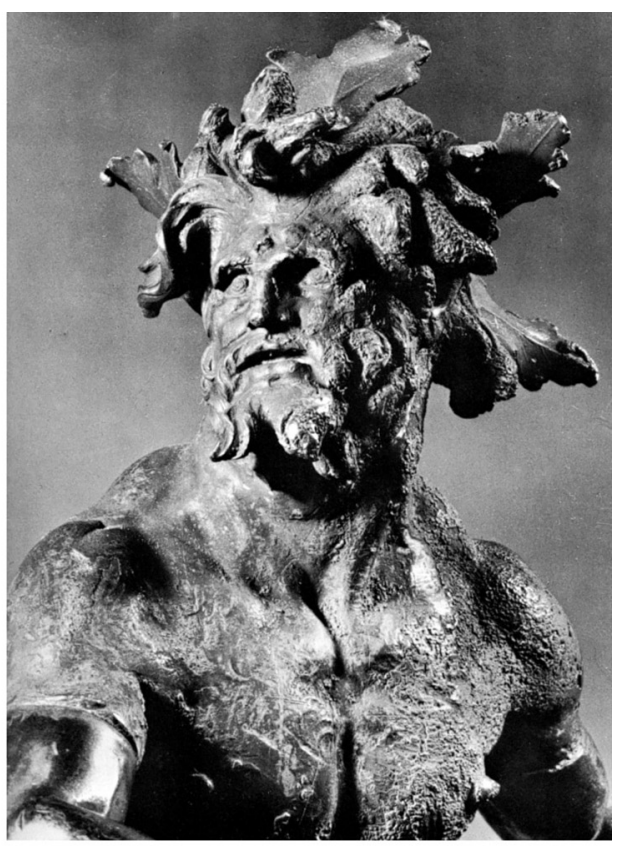

EsT. V-2

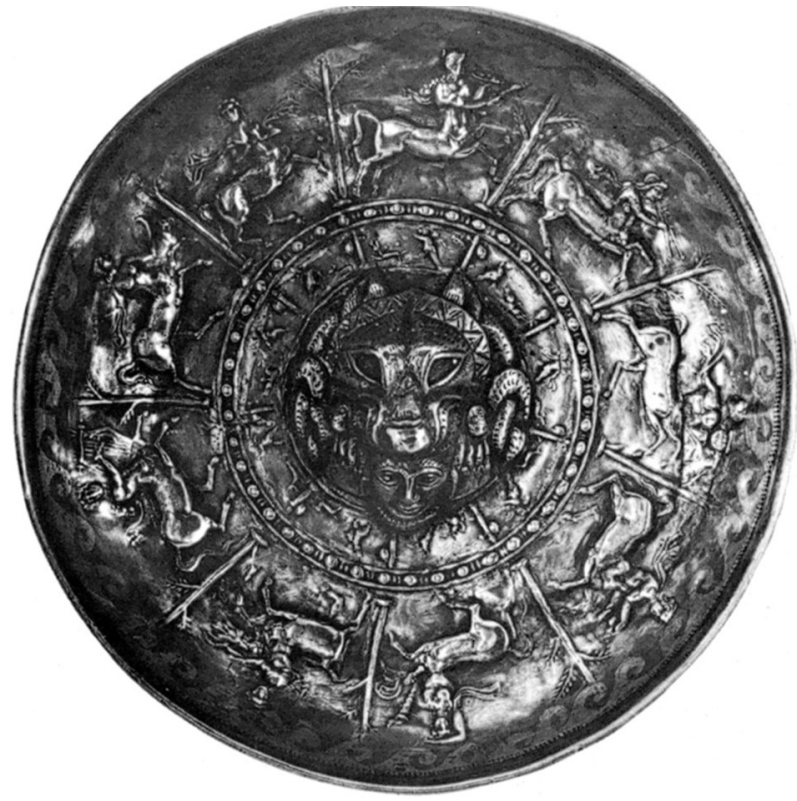

EsT. V-3 
它

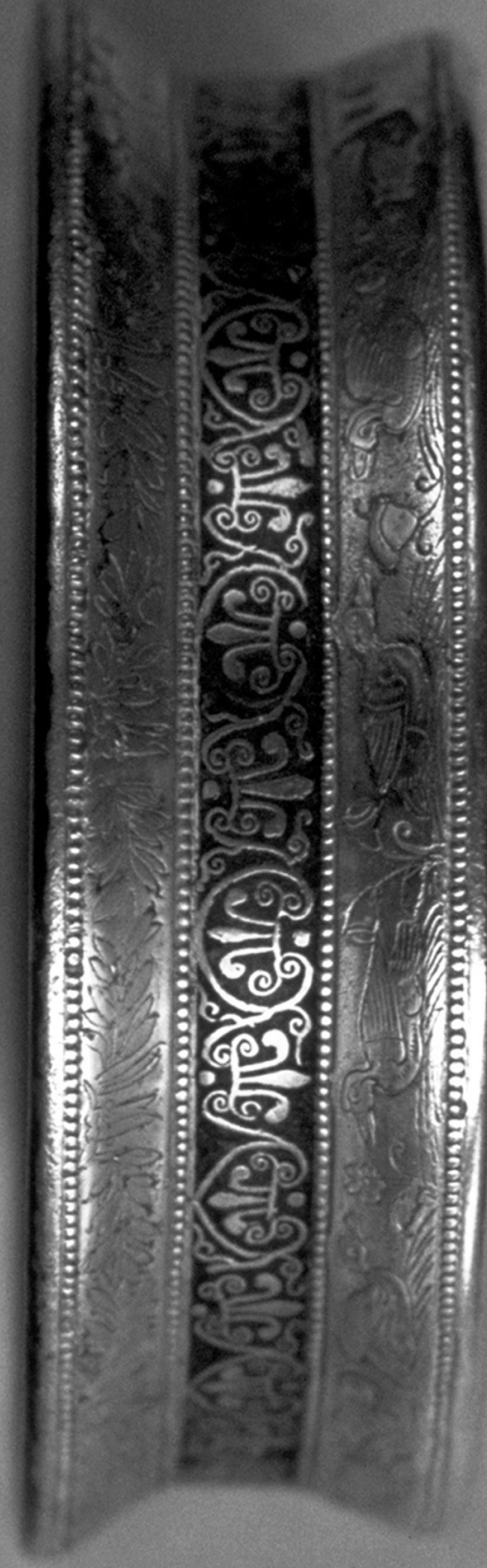




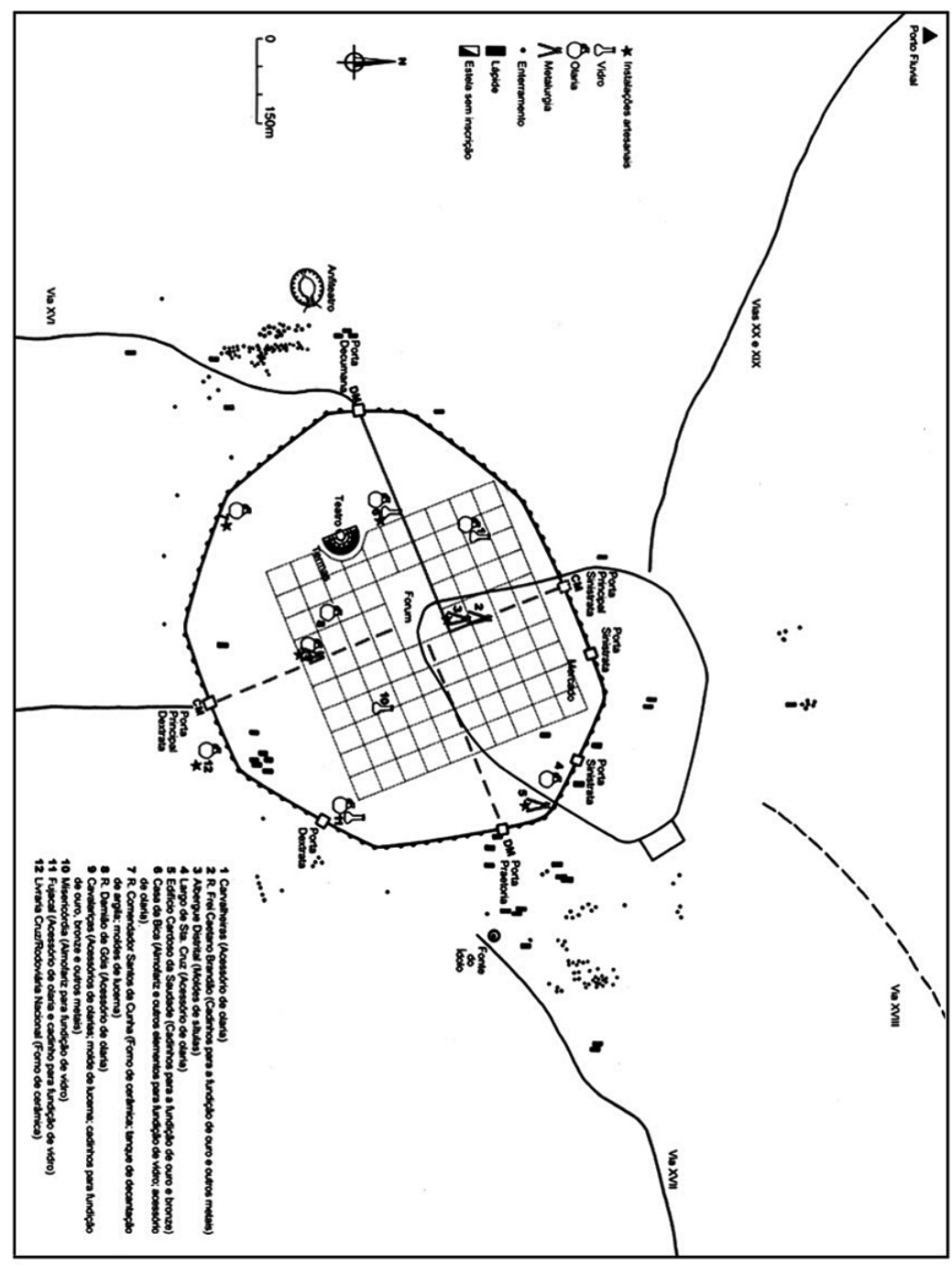


EsT. VIII

EsT. VIII-1
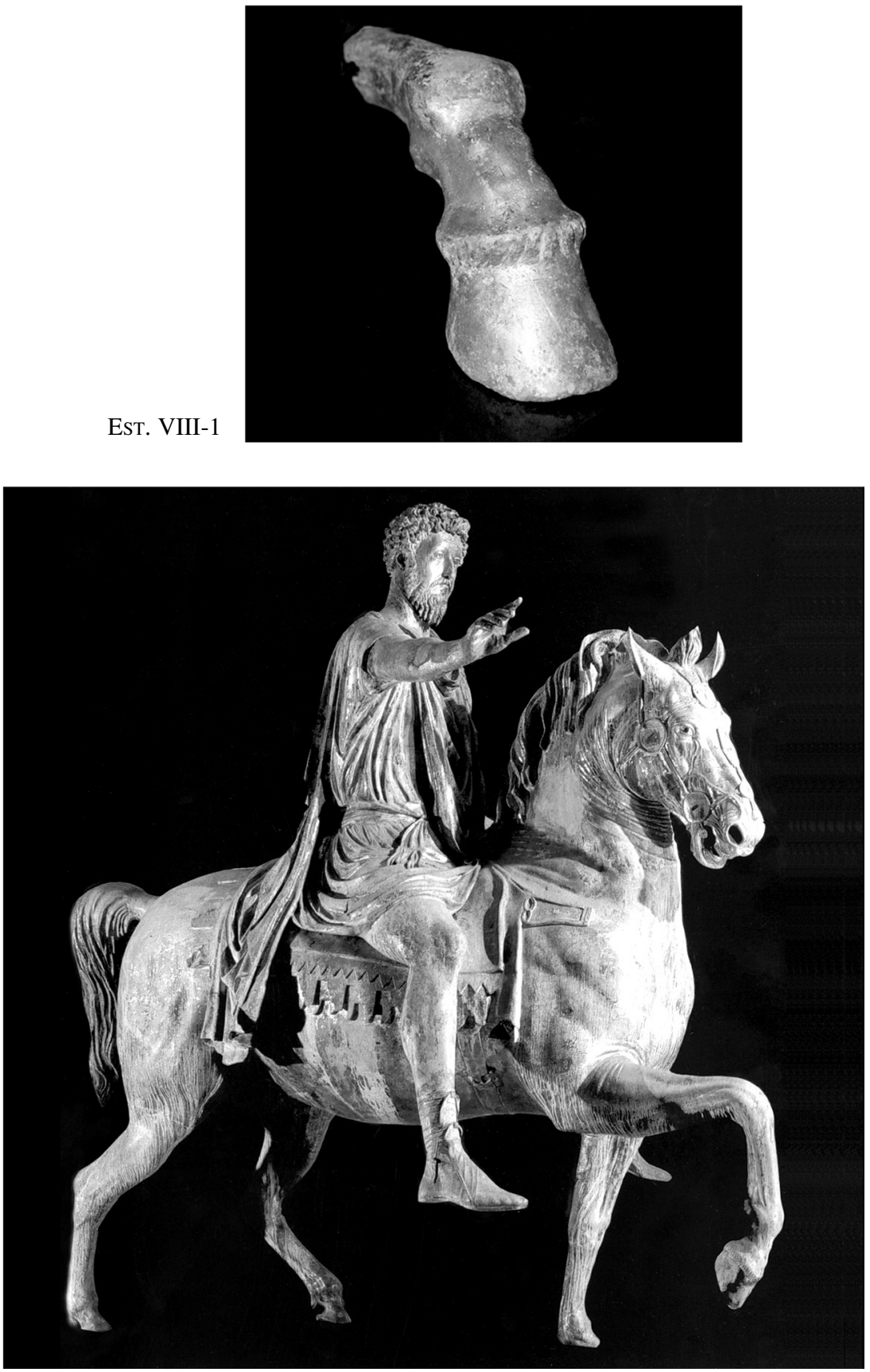

EsT. VIII-2 